zuerst ausgestellt war, zeigt, obgleich Probe 1 nachweislich über zwei Jahre alt ist, eine Ranzigkeit von nur $0,85^{\circ}$. Es ist hier ein Fett verwendet, welches zum Ranzigwerden wenig neigt, und dieses Beispiel, wie die schon oben angeführte Thatsache, dass ausser Cocosnussbutter besonders Oleomargarin stets nur geringe Ranzigkeit zeigt, dürfte den Fabrikanten vielleicht ein Fingerzeig sein, der Verwendung dieser Fette einen grösseren Spielraum als bisher bei der Herstellung derartiger Dauerpräparate einzuräumen. Das von dem Stearin durch Auskrystallisiren und Abpressen befreite Oleomargarin hat ausser seiner geringen Neigung zum Ranzigwerden auch uoch den Vortheil der leichten Schmelzbarkeit und leichten Verdaulichkeit.

Ein Punkt, der bei der Untersuchung der Conserven neben der Ranzigkeit noch erwähnt zu werden verdient, ist der Bakte-. riengehalt. Es wurden in einzelnen Fällen, besonders bei No. 5,6 und 8 reichlich Mikroorganismen gefunden. Es wäre wichtig zu wissen, ob der Gebalt an Mikroorganismen mit der Zunahme der Ranzigkeit steigt oder ob ein Zusammenhang zwischen beiden nicht besteht. Das Ranzigwerden selbst, welches man bisher theilweise auf eine durch die Luft herbeigeführte Oxydationswirkung, theilweise auf die Mitwirkung der Bakterien zurückgeführt hat, ist kürzlich wieder von Ed. Ritsert studirt (Untersuchungen über das Ranzigwerden der Fette), und kommt derselbe zu dem Schlusse, dass das Ranzigwerden reinen Fettes ein directer Oxydationsprocess ist, bedingt durch den Sauerstoff der Luft. Auf alten ranzigen Fetten kommen die verschiedenartigsten lebensfähigen Keime, hauptsächlich Schimmelpilze, Oidien und Hefen vor; doch sollen dieselben auf sehr stark ranzigen Fetten nicht mehr leben können. Ritsert führt einen Fall an, in welchem auf Palmöl, welches $120^{\circ}$ Ranzigkeit hatte, nicht einmal Schimmelpilze mehr wuchsen. $\mathrm{Ob}$ ein ähnliches Verhalten aber auch bei den Conserven stattfindet, erscheint zweifelbaft.

Kurz zusammengefasst würden sich aus der vorstehenden Mittheilung folgende Sätze hervorheben lassen.

\section{a) Suppenconserven.}

Die Ranzigkeit der Suppenconserven des Handels ist sehr verschieden; dieselbe schwankt nach den gemachten Beobachtungen von $0,8^{\circ}$ bis $45^{\circ}$.

Beim Genuss in Suppenform macht sich die Ranzigkeit im Geschmack erst bei einem Säuregrad von etwa $12^{\circ}$ bemerkbar. Präparate mit höherem Säuregehalt sind als schlechte Handelswaare zu bezeichnen. Die Ranzigkeit, welche eine als, ,ver- dorben" zu bezeichnende Conserve zeigen muss, ist einstweilen mit Sicherheit nicht anzugeben.

Line Vermeidung des Ranzigwerdens durch Auswahl geeigneter Fette erscheint möglich.

\section{b) Butter.}

Eine Vereinbarung über den zulässigen Ranzigkeitsgrad der Butter erscheint nothwendig.

Da die Ranzigkeitszahl nicht immer der Ausdruck für die Höhe des ranzigen Geschmacks ist, da auch ein strenger Unterschied 7wischen Essund Kochbutter nicht gemacht werden kann, so ist die Grenze für den zulässigen Ranzigkeitsgrad nicht zu niedrig zu ziehen.

\section{Über Gnttmann's Verbesserungen in der SaIpetersäure-Fabrikation.}

Man kann wohl kaum verlangen, dass ich alle Einzelheiten widerlege, welche Herr Andersch auf S. 619 d. Z. vorbringt, ohne meine Abhandlung genügend verstanden zu haben; ich beschränke mich deshalb auf Weniges.

Ich habe ausdrücklich vorausgeschickt, dass man die Beschickung nicht so stark erhitzen darf, dass blos festes neutrales Sulfat übrigbleibt, oder Gefahr für Thonwaaren und Eisengefässe eintritt, konnte also von Sachverständigen annehmen, dass sie wissen, was man unter "beliebig heissem" Arbeiten verstehe. Herr Andersch arbeitet z. B. zwischen 80 und $120^{\circ}$, also mit grossem Spielraume.

Herrn Andersch kommt es auf ein Paar Quadratmeter Gebäudefläche nicht an. Da er eine Retorte mit $300 \mathrm{k}$ Salpeter beschickt und nur 5 Tourilles verwendet, so wird er (auch dann, wenn er, wie ich, keine schwächere Säure erzielt) 8 Retorten benöthigen, um $1750 \mathrm{k} 48^{\circ}$ Salpetersäure in einer Beschickung $\mathrm{zu}$ erzeugen, und es werden 48 Stunden vergehen, ehe er bei seiner langsamen Arbeit eine zweite Beschickung machen kann. Dies würde also 16 Retorten für tägliche $1750 \mathrm{k}$ $48^{\circ}$ Säure bedeuten, und dazu sind ihm 80 Tourilles erforderlich; sind das wirklich nur ein Paar Quadratmeter mehr, und hat er dann in der That weniger Kittstellen, als bei meinen 4 Retorten und 40 Röhren? Sollte diese Anlage wirklich nur $30000 \mathrm{M}$. kosten?

Eine Antwort darauf ist wohl nicht nöthig, aber Eines möchte ich gern wissen: Warum nehmen gerade offenbare Neulinge einen so herablassend ironischen Ton au, wenn sie uns belehren wollen?

London, 21. October 1890.

$$
\text { Oscar Guttmann. }
$$

